\title{
SPUTUM CYTOLOGY IN BRONCHOGENIC CARCINOMAS
}

Agrawal R. $^{1}$
Jain Y. K. ${ }^{2}$

\section{ABSTRACT:}

Sputum cytology is an important investigation in the diagnosis of lung malignancies. The study was thus aimed at evaluating the role of sputum smears in bronchogenic carcinomas. A total of 80 cases were included in the study. The positivity rate for various subtypes was squamous cell carcinoma $(\mathbf{5 0 \%})$, large cell carcinoma $(\mathbf{5 0 \%})$, non-hodgkins lymphoma $(50 \%)$, secondaries $(\mathbf{4 0 \%})$, small cell carcinoma $(37.5 \%)$, hodgkins lymphoma $(33.33 \%)$ and adenocarcinoma $(30.77 \%)$. Peripherally located malignant lesions have a reduced chance of being expectorated out in the sputum. Early morning samples are the best sample for diagnosis.

It was thus concluded that Sputum cytology is important as an investigation to be carried out simultaneously with other techniques in detecting occult malignancies.

\section{KEY WORDS: Sputum Cytology, Bronchogenic Carcinoma}

\section{INTRODUCTION:}

Despite the availability of numerous newer investigations, diagnosis of lung malignancies remains difficult. Cytology provides an useful and usually adequate diagnostic means. It may be in the form of sputum or fine needle aspiration (FNA)- unguided or guided. The present study was carried out with the aim of evaluating the role of sputum cytology in identification of lung malignancies and also in their sub-typing. An attempt has also been made to compare the results of sputum cytology with histology.

1. MD (Path); MRBA, Assistant Professor, Pathology, Manipal College of Medical Sciences, Pokhara, Nepal. 2. MS (Gen. Surg.); F.R.C.S. (London), Consultant Surgeon, Wigan, U.K.

Address for correspondence : Dr. Ranjan Agrawal, Assistant Professor, Department of Pathology Manipal College of Medical Sciences

Post Box: 155, Deep Heights, Pokhara, Nepal.

Tel: 00977-61-21555 (Res.), Fax: 00977-61-26060

Email: ragrawal@mos.com.np 


\section{MATERIAL AND METHODS:}

A pilot study was carried out in a one year period. All patients with intrathoracic masses demonstrated by X-Ray, CT scan or Ultrasonography were included in this study. Patients of both the sexes and all age groups were included. A detailed clinical evaluation was done in all the patients with special reference to examination of the respiratory system. Sputum was obtained from these patients. Early morning sample was preferred. At times induced samples were obtained. During prolonged hospital stay multiple samples were obtained. Histology was simultaneously carried out in these patients to compare the results with that of sputum cytology.

\section{OBSERVATIONS :}

Of the total 80 cases of malignancy diagnosed by histology, 31 (38.75\%) were picked up by sputum cytology (Table). The maximum rate was observed in squamous cell carcinoma, large cell carcinoma and non-hodgkins lymphoma (50\% each). The lowest rate observed was in adenocarcinoma (30.77\%). Hodgkins lymphoma also had a low rate in sputum smears. On combining both the lymphomas, the positivity rate observed was $37.5 \%$.

\section{SPUTUM CYTOLOGY IN MALIGNANT LESIONS OF LUNG}

TUMOUR TYPE $n$ SPUTUM POSITIVE SPUTUM NEGATIVE

\begin{tabular}{lccccc} 
& & $\mathbf{n}$ & $\mathbf{\%}$ & $\mathbf{n}$ & $\mathbf{\%}$ \\
\hline Adenocarcinoma & 26 & 8 & 30.77 & 18 & 69.23 \\
Squamous cell carcinoma & 16 & 8 & 50.00 & 8 & 50.00 \\
Small cell carcinoma & 16 & 6 & 37.50 & 10 & 62.50 \\
\hline Large cell carcinoma & 4 & 2 & 50.00 & 2 & 50.00 \\
Hodgkin's Lymphoma & 6 & 2 & 33.33 & 4 & 66.67 \\
Non-Hodgkin's Lymphoma & 2 & 1 & 50.00 & 1 & 50.00 \\
\hline Secondaries & 10 & 4 & 40.00 & 6 & 60.00 \\
TOTAL & 80 & 31 & 38.75 & 49 & 61.25 \\
\hline
\end{tabular}

\section{DISCUSSION:}

Overall, only $38.75 \%$ of malignant cases gave positive sputum cytology, a rate similar to that reported earlier, ${ }^{1}$ but lower than those of others. ${ }^{2-5}$ Most of our cases furnished a single sample of sputum, obtained just prior to the biopsy sample. The positivity rate varies directly with the number of samples per case. In few of our cases where multiple sputum samples were obtained, the result showed marked variation. It was not possible to collect multiple samples as most of the patients were not admitted in the wards. Also, not all patients had a history of cough and requesting such patients especially those with dyspnoea for more than one sputum sample was not feasible. Other authors have also reported an increase in positively with multiple samples. ${ }^{6,7}$ Although, early morning sample of sputum furnished good results, it is difficult to obtain, as most of the patients presented in the out-door clinic.

The sensitivity for adenocarcinoma observed in our study was $30.77 \%$, a rate lower than other malignancies. Similarly lowest rates were reported earlier also..$^{\mathbf{- 1 0}}$ The likely reason for this may be the peripheral location and smaller size of the tumour. ${ }^{11}$ The best sensitivity was observed in the central lesions - squamous cell carcinoma, large cell carcinoma and non-hodgkins lymphoma. Exact subcategorisation of hodgkins lymphoma may be difficult on sputum smears, because of difficulty in demonstrating classical Reed-Sternberg giant cells. However, presence of mononuclear Hodgkins cell or eosinophils lead to the the diagnosis. Demonstration of Reed-Sternberg cells is a must. Similarly, classification of Non-Hodgkins lymphoma may pose great difficulties for the cytopathologists. There is no clear cut distinction between the peripheral and central lesions as some workers divide this on anatomic grounds, ${ }^{8}$ while others on bronchoscopic criteria. ${ }^{9}$

Certain factors need to be taken care of viz. necrotising nature of the tumour, associated inflammation, preservation status of the sample and size 
of tumour. Large sized tumours are easily picked up on sputum examination. Malignant cells are liable for early degeneration especially in the summers. So, adequate sample preservation in a proper fixative is essential.

One area where sputum cytology dominates over fine needle aspiration cytology (FNAC) is in the detection of occult malignancies, an observation also made by other workers. ${ }^{10,11}$ However, since nowadays most of the aspirations are carried out in radiologically isolated lung tumours, the incidence of occult carcinoma is reduced.

\section{CONCLUSION:}

This study helped us in concluding that sputum cytology is an important tool in the detection of lung malignancies both as a primary mode of investigation and also as an additional step with other procedures. Histology, the 'gold standard' is not possible in all the cases.

\section{REFERENCES:}

1. Jain YK, Gupta SC, Singh PA, Agrawal R, Mishra JK: FNAC in Intrathoracic lesions. J Cytol 14(1):15-19, 1997.

2. Spurune H, Pedio Co, Ruthner JR: The diagnostic reliability of cytological sub-typing in primary lung cancer with review of literature. Acta Cytol 24: 494-500, 1980.

3. Nasiell M: Diagnosis of lung cancer by aspiration biopsy and comparison between this method and exfoliative cytology. Acta Cytol 11:114-119, 1967.
4. Koss LG: Diagnostic cytology and its histopathologic basis, $3^{\text {rd }}$ ed, Philadelphia J.B Lippincott 1195-1201, 1979.

5. Pilloti S et al : Sputum cytology for diagnosis of carcinoma of lung. Acta Cytol 26:649654, 1982.

6. Lange E, Hoeg MD: Cytological typing of lung cancer. Acta Cytol 16:327-331, 1972.

7. Perlman EJ, Erozan YS, Howdon AH: the role of Saccomanno techniwue in sputum cytolopathologic diagnosis of lung cancer. Am J Clin Patho 91:57-60, 1989.

8. Dahlgren SE, Lind B: comparison between diagnostic results obtained by transthoracic needle biopsy and by sputum cytology. Acta Cytol 16:53-58, 1972.

9. Jay SJ, Wehr K, Nicholson DP, Smith AL: Diagnostic sensitivity and specificity of pulmonary cytology - Comparison of techniques used in conjunction with flexible fibreoptic bronchoscopy. Acta Cytol 24:304-312, 1980.

10. Gagnetan CB, Geller CE, Saenz MC: Diagnosis of bronchogenic carcinoma excluding adenocarcinoma. Acta Cytol 26:645648, 1982.

11. Gupta RK: Value of sputum cytology and typing of bronchogenic carcinoma excluding adenocarcinoma. Acta Cytol 26:645648, 1982. 